\title{
Correlation between Intraoperative Ossicular Status and Conductive Hearing Loss Degree among Chronic Suppurative Otitis Media Patients in Dr Mohammad Hoesin General Hospital Palembang
}

\author{
Rizandiny ${ }^{1 *}$, Ahmad Hifni ${ }^{1}$, Erial Bahar ${ }^{2}$, Abla Ghanie ${ }^{1}$ \\ ${ }^{1}$ Department of Otorhinolaryngology, Faculty of Medicine, Universitas Sriwijaya, Palembang, Indonesia \\ ${ }^{2}$ Department of Anatomy, Faculty of Medicine, Universitas Sriwijaya, Palembang, Indonesia
}

\section{A R T I C L E I N F O}

Keywords:

Chronic Suppurative Otitis Media

Ossicular Status

Conductive Hearing Loss

\section{*Corresponding author: \\ Rizandiny \\ E-mail address: rizandiny@gmail.com}

All authors have reviewed and approved the final version of the manuscript.

https://doi.org/10.32539/bsm.v5i4.409

\begin{abstract}
A B S T R A C T
Background: Chronic suppurative otitis media (CSOM) is a chronic inflammation of the mucosa and periosteum of the middle ear and mastoid cavity that defined as a perforated tympanic membrane with persistent drainage for more than 2 months. Preoperative hearing threshold and air bone gap (ABG) assessment are expected to predict the ossicular status which can only be ascertained intraoperatively. This study aimed to determine the correlation between intra-operative ossicular status and the degree of conductive hearing loss assessed based on the hearing threshold and average ABG among CSOM patients in RSUP Dr. Mohammad Hoesin Palembang. Methods: Observational research using a cross sectional design. The data were collected using medical record on 64 subjects with a diagnosis of CSOM who underwent mastoidectomy surgery at Dr. Mohammad Hoesin Hospital Palembang for the period of March 2019 to June 2021. Results: From 64 samples conducted in the study, the average ossicular status score in CSOM patients was $1.84 \pm 1.48$, with the highest group scoring 0 being the malleus incus and intact stapes as many as 21 patients $(31.3 \%)$. There was a strong positive correlation between hearing threshold scores and intra-operative ossicular status scores $(\mathrm{p}<0.005, \mathrm{R}=0.5)$ and there was a strong positive correlation between ABG scores and intra-operative ossicular status scores ( $\mathrm{p}$ $<0.005, \mathrm{R}=0.6$ ). From the linear regression test, the most influential in predicting intra-operative ossicular status scores were gender, hearing threshold value, ABG value, and the presence of cholesteatoma. Conclusions: There is a significant relationship between intra-operative ossicular status and the degree of conductive hearing loss in CSOM patients.
\end{abstract}

\section{Introduction}

Chronic suppurative otitis media (CSOM) is a chronic inflammation of the mucosa and periosteum of the middle ear and mastoid cavity that lasts more than 2 months. CSOM manifestations in the form of continuous or intermittent otorrhoea from the perforated tympanic membrane. CSOM is still a major health problem, especially in developing countries including Indonesia. CSOM is associated with a high level of morbidity, one of which is hearing loss. As many as $80 \%$ of CSOM sufferers have hearing loss. Hearing loss is the total or partial inability to hear sound in one or both ears. ${ }^{1-4}$

Types of hearing loss that occur in CSOM can vary between conductive, sensorineural, or a mixture of both. However, the most common form of hearing loss in CSOM is conductive. Conductive hearing loss is a manifestation of impaired sound wave transmission due to disruption of the integrity and mobility of the sound delivery system due to perforation of the tympanic membrane and damage to the auditory or ossicular bones due to chronic inflammation of the middle ear. Ossicular discontinuity is a consequence of CSOM and often occurs in about one-third of all CSOM cases.

Chronic middle ear inflammation occurs due to overproduction of cytokines such as TNF-, interleukin2 , fibroblast growth factor, and platelet-derived growth factor. This promotes hypervascularization, osteoclast 
activation and bone resorption leading to ossicular damage. High-resolution computer tomography can depict the ossicles but is not a definitive preoperative investigation. Ossicular status can only be demonstrated at surgery. ${ }^{5-9}$

Pure tone audiometry or Pure tone audiometry (PTA) is a routine examination before surgery to assess auditory function in patients with pre-operative Omsk. Preoperative assessment is a method of confirming ossicular status, and it is helpful if it can be predicted prior to surgery. Sheikh et al said that intra-operative ossicular status is expected to be predictable with pure tone audiometric images which are needed as a basis for selecting surgical technique, a basis for exploration of the ossicular sequence and reconstruction whenever possible. In addition, prediction of ossicular status is also needed to determine the prognosis of CSOM.7,9,10

\section{Methods}

This research is an observational study using a cross sectional study design and aims to find a correlation between intra-operative ossicular status and the degree of conductive hearing loss in CSOM patients at Dr. Mohammad Hoesin (RSMH) Palembang. The study population was all patients who had been diagnosed with CSOM and underwent mastoidectomy surgery at Dr. RSUP. Mohammad Hoesin Palembang during the period March 2019 to June 2021.

Sampling was carried out by total sampling. In this study, 64 patients met the inclusion criteria. The inclusion criteria of the sample were patients diagnosed with CSOM at RSMH Palembang who underwent pure tone audiometry examination with conductive hearing loss results, patients underwent mastoidectomy surgery and complete medical record data. While the exclusion criteria were patients diagnosed with CSOM at RSMH accompanied by congenital ear abnormalities, age less than 5 years and more than 60 years, patients experiencing otitis externa, and pure tone audiometry results of mixed type hearing loss, sensorineural type and hearing loss with hearing threshold above $60 \mathrm{~dB}$.

Data analysis in this study used the SPSS 24.0 application. The analysis consisted of univariate, bivariate and multivariate analysis. Univariate analysis was carried out to see the characteristics of the research subjects and the frequency distribution. Bivariate analysis for the correlation of hearing threshold values and ABG scores with intraoperative ossicular status scores in CSOM patients and knowing the confounding variables associated with the independent and dependent variables. Multivariate analysis to control for confounding variables. Multivariate analysis was carried out if in the bivariate analysis there were variables that had a $\mathrm{p}$ value of < 0.25 . The results of the data analysis are presented in the form of a table accompanied by a narration.

\section{Results}

A total of 64 patients were included in this study consisting of 31 male patients (48.4\%) and 33 female patients $(51.6 \%)$. The mean age of the subjects was 28 years. Based on the age category, most of the research subjects were in the 15-30 year age group, as many as 32 patients (50\%). Based on the length of illness, the most subjects were in the group $\geq 5$ years, namely 44 patients $(68.7 \%)$. Based on the intra-operative ossicular status, the majority of subjects had type $\mathrm{O}$ $(\mathrm{M}+\mathrm{I}+\mathrm{S}+)$ as many as 20 patients $(31.3 \%)$. The most common type of tympanic membrane perforation was the subtotal type, as many as 24 subjects (37.5\%). Based on the presence or absence of cholesteatoma, 36 subjects had cholesteatoma (56.3\%). Based on the presence or absence of granulation tissue, 48 patients had granulation tissue $(75 \%)$. The average hearing threshold as measured by pure tone audiometry was $44.05 \pm 10.27 \mathrm{~dB}$. The highest group was in the range of 41-55 dB or moderate degree of hearing loss, namely 34 patients (53.1\%). The average ABG of all subjects was $28.92 \pm 10.56 \mathrm{~dB}$ with the highest group being < $40 \mathrm{~dB}$, namely 52 patients (81.3\%). The average score of ossicular status was $1.84 \pm 1.48$ with the highest group being scored 0 as many as 21 patients (31.3\%). 
Table 1. Subject characteristics table

\begin{tabular}{|c|c|c|c|}
\hline Variable & Frequency (f) & Percentage (\%) & $\mathrm{X} \pm \mathrm{SD}$ \\
\hline \multicolumn{4}{|l|}{ Age } \\
\hline $5-15$ years & 9 & 14.1 & \multirow{4}{*}{$28.09 \pm 12.38$} \\
\hline $16-30$ years & 32 & 50 & \\
\hline $31-45$ years & 15 & 23.4 & \\
\hline $45-60$ years & 8 & 12.5 & \\
\hline \multicolumn{4}{|l|}{ Gender } \\
\hline Male Male & 31 & 48.4 & \\
\hline Female & 33 & 51.6 & \\
\hline \multicolumn{4}{|l|}{ Hearing Threshold } \\
\hline$\leq 25 \mathrm{~dB}$ & 4 & 6.2 & \multirow{4}{*}{$44.05 \pm 10.27$} \\
\hline$\overline{26}-40 \mathrm{~dB}$ & 17 & 26.6 & \\
\hline $41-55 \mathrm{~dB}$ & 34 & 53.1 & \\
\hline $56-60 \mathrm{~dB}$ & 9 & 14.1 & \\
\hline \multicolumn{4}{|l|}{ Air-Bone Gap } \\
\hline$<40 \mathrm{~dB}$ & 52 & 81.3 & \multirow{2}{*}{$28.92 \pm 10.56$} \\
\hline$\geq 40 \mathrm{~dB}$ & 12 & 18.7 & \\
\hline \multicolumn{4}{|l|}{ Ossicular Circuit Status } \\
\hline Type O (M+I+S+) & 20 & 31.3 & \\
\hline Type A $(\mathrm{M}+\mathrm{S}+)$ & 6 & 9.4 & \\
\hline Type B (M+S-) & 2 & 3.1 & \\
\hline Type C (M-S+) & 4 & 6.3 & \\
\hline Type D (MS-) & 9 & 14.1 & \\
\hline Type E (Ossicular head fixation) & 9 & 14.1 & \\
\hline \multicolumn{4}{|l|}{ Type F (Stapes fixation) } \\
\hline & & & \\
\hline \multicolumn{4}{|l|}{$\begin{array}{l}\text { Intra-operative ossicular status score } \\
0\end{array}$} \\
\hline 1 & 20 & 31.3 & \multirow{5}{*}{$1.84 \pm 1.48$} \\
\hline 2 & 6 & 9.4 & \\
\hline 3 & 11 & 17.2 & \\
\hline 4 & 18 & 28.1 & \\
\hline & 9 & 14.1 & \\
\hline \multicolumn{4}{|l|}{ Duration of illness } \\
\hline$<5$ years & 20 & 31.3 & \\
\hline$\geq 5$ years & 44 & 68.7 & \\
\hline \multicolumn{4}{|l|}{ Type of perforation } \\
\hline \multicolumn{4}{|l|}{ Tympanic membrane } \\
\hline Atik & 9 & 14.1 & \\
\hline Marginal & 1 & 1.6 & \\
\hline Central & 19 & 29.6 & \\
\hline Subtotal & 24 & 37.5 & \\
\hline Total & 11 & 17.2 & \\
\hline \multicolumn{4}{|l|}{ Cholesteatoma } \\
\hline No & 28 & 43.7 & \\
\hline Yes & 36 & 56.3 & \\
\hline \multicolumn{4}{|l|}{ Granulation Network } \\
\hline No & 16 & 25.0 & \\
\hline Yes & 48 & 75.0 & \\
\hline
\end{tabular}


Table 2 shows the pattern and strength of the correlation of each limited score ap listening threshold value numerically. In the hearing threshold variable, the ossicular status score of 0 has a p-value of 0.001 and a correlation strength of -0.418 . There is a significant relationship between a score of 0 ossicular status to the hearing threshold value and there is a moderate negative correlation. That is, if an ossicular status score of 0 is obtained, it will reduce the hearing threshold value of OSMK patients. In addition, the score of ossicular status 3 has a p value of 0.002 and a correlation strength of 0.382 and a score of ossicular status 4 has a p value of 0.04 and a correlation strength of 0.256. There is a significant relationship between a score of 3 and a score of 4 ossicular status on the hearing threshold value and there is a moderately strong positive correlation on a score of 3 and a weak strength on a score of 4 . This means that if an ossicular status score of 3 or 4 is obtained, it will increase the hearing threshold value of CSOM patients.

Table 2. Patterns and correlation coefficients of the relationship between the intraoperative ossicular status of each score and the hearing threshold.

\begin{tabular}{ccc}
\hline Variable & \multicolumn{2}{c}{ Hearing Threshold } \\
\cline { 2 - 3 } & P-value & Correlation coefficient (R)* \\
\hline Ossicular status score 0 & 0.001 & -0.418 Oscular \\
\hline status score 1 & 0.385 & \\
\hline Oscular status score 2 & 0.853 Oscular & 0.382 \\
\hline status score 3 & 0.002 & 0.256 \\
\hline Oscular status score 4 & 0.041 & \\
\hline
\end{tabular}

*Correlation spearman

Table 3 shows the pattern and the strength of the correlation of each score to the ABG value. In the ABG variable, the ossicular status score of 0 has a $p$ value of $<0.005$ and the strength of the correlation is -0.552 . There is a significant relationship between a score of 0 ossicular status and the ABG value and there is a strong negative correlation. That is, if an ossicular status score of 0 is obtained, it will reduce the $A B G$ value of OSMK patients. In addition, the ossicular status score 3 has a $\mathrm{p}$ value $<0.005$ and a correlation strength of 0.541 . There is a significant relationship between a score of 3 ossicular status and the ABG score and there is a strong positive correlation with a score of 3 . That is, if a score of 3 ossicular status is obtained, it will increase the ABG value of CSOM patients.

Table 3. Pattern and correlation coefficient of the relationship between intra-operative ossicular status of each score with ABG

\begin{tabular}{ccc}
\hline Variable & & Air-Bone Gap \\
\cline { 2 - 3 } & P-value* & Correlation coefficient (R)* \\
\hline Ocular status score 0 & $<0.005$ & -0.552 Ocular \\
\hline status score 1 & 0.385 & \\
\hline Oscular status score 2 & 0.853 & \\
\hline status score 3 & ossicular & 0.541 \\
\hline ossicular status score 4 & $<0.005$ & \\
\hline${ }^{*}$ Correlation spearman & 0.223 & \\
\hline
\end{tabular}

\footnotetext{
${ }^{*}$ Correlation spearman
} 
Table 4 shows the correlation analysis of Spearman the overall intra-operative ossicular status score with hearing threshold and ABG. The correlation between hearing threshold and ossicular status score was < 0.005 with a correlation strength of 0.536. That is, there is a significant relationship between hearing threshold values and ossicular status scores with the strength of a strong relationship. The higher the hearing threshold value, the higher the ossicular status score and vice versa. ABG correlation with ossicular status score was $<0.005$ with a correlation strength of 0.604. That is, there is a significant relationship between ABG scores and ossicular status scores with the strength of a strong relationship. The higher the $\mathrm{ABG}$, the higher the ossicular status score and vice versa.

Table 4. Table of hearing threshold correlation test and ABG on intraoperative ossicular status score

\begin{tabular}{ccc}
\hline & \multicolumn{2}{c}{ Intra-operative ossicular status score $^{\text {Variable }}$} \\
\cline { 2 - 3 } & P-value $^{*}$ & Correlation coefficient (R)* $^{*}$ \\
\hline Hearing Threshold & $<0.005$ & 0.536 \\
\hline Air-Bone Gap & $<0.005$ & 0.604 \\
\hline
\end{tabular}

${ }^{*}$ Correlation spearman

Table 5. Variable determination of multivariate analysis

\begin{tabular}{|c|c|c|}
\hline Variable & Category & p value ${ }^{* *}$ \\
\hline Age & $\begin{array}{l}5-15 \text { years old } \\
16-30 \text { years old } \\
31-45 \text { years old } \\
45-60 \text { years old }\end{array}$ & 0467 \\
\hline Gender & $\begin{array}{l}\text { Male } \\
\text { Female }\end{array}$ & 0092 * \\
\hline Old ill & $\begin{array}{l}<5 \text { years } \\
\geq 5 \text { year }\end{array}$ & 0.74 \\
\hline $\begin{array}{l}\text { Tympanic } \\
\text { perforation type }\end{array}$ & $\begin{array}{ll} & \text { Atik } \\
& \text { Marginal } \\
\text { membrane } & \text { Central } \\
& \text { Subtotal } \\
& \text { Total }\end{array}$ & $0: 35$ \\
\hline Cholesteatoma & $\begin{array}{l}\text { No } \\
\text { Yes }\end{array}$ & 0035 * \\
\hline Granulation tissue & $\begin{array}{l}\text { No } \\
\text { Yes }\end{array}$ & 0.092 * \\
\hline Hearing thresholds & $\begin{array}{l}\leq 25 \mathrm{~dB} \\
26-40 \mathrm{~dB} \\
41-55 \mathrm{~dB} \\
56-60 \mathrm{~dB}\end{array}$ & $<0.005 *$ \\
\hline Air-Bone Gap & $\begin{array}{l}<40 \mathrm{~dB} \\
\geq 40 \mathrm{~dB}\end{array}$ & $<0.005 *$ \\
\hline
\end{tabular}


Table 6. Multivariate linear regression analysis

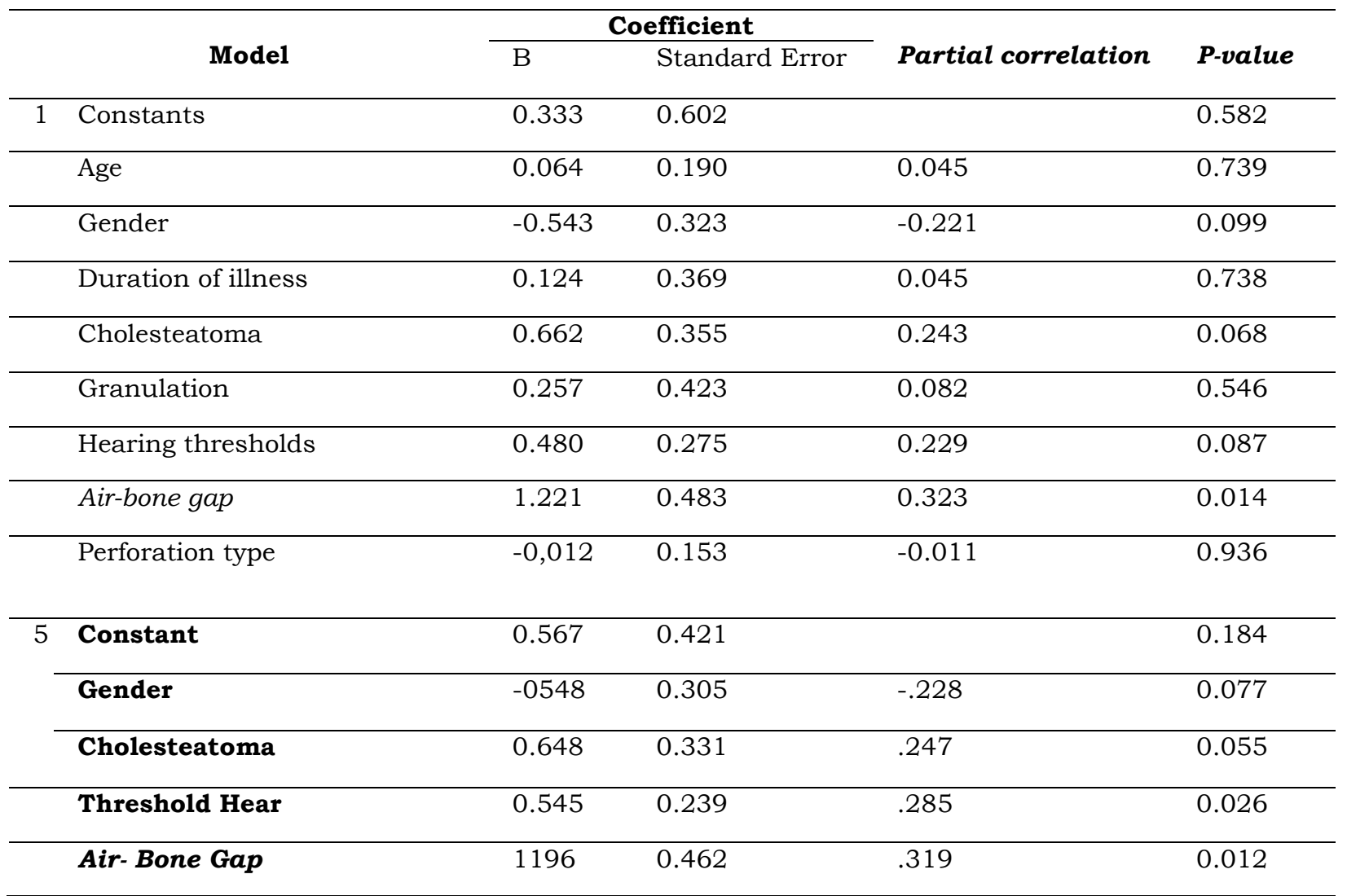

This shows that the linear regression equation can be used to predict the effects of independent variables on the dependent variable, namely score ossicular intra-operative status and this shows that there is significant influence of four independent variables simultaneously affecting the dependent variable. The combination of the most influential factors is formulated with the final equation as follows:

$\mathrm{Y}=\mathrm{K}+0.648\left(\mathrm{X}_{2}\right)+0.545\left(\mathrm{X}_{3}\right)+1.196\left(\mathrm{X}_{4}\right)-0.548\left(\mathrm{X}_{1}\right)$ Information:

$\mathrm{Y}=$ score of intra-ossicular status operative

$\mathrm{X} 1=$ Gender $(1=$ male, $0=$ female $)$

X2 = cholesteatoma $(1=$ no, $0=$ no $)$

X3 = Threshold heard $(1=26-40 \mathrm{~dB}, 2=41-55 \mathrm{~dB}$, $3=56=60 \mathrm{~dB}$, $0=\leq 25 \mathrm{~dB})$

X4 = ABG $(1=\geq 40 \mathrm{~dB}, 0=<40 \mathrm{~dB})$

$\mathrm{K}=$ Constant $=0.567$

The $\mathrm{Y}$ value obtained if it is assumed that CSOM patients have cholesteatoma (1), have a hearing threshold of 56-60 dB (3), having ABG $\geq 40 \mathrm{~dB}$ (1), and female patients (0), is $\mathbf{4}$ with the following calculation:

$\mathrm{Y}=0.567+0.648+1.635+1.196$

$\mathbf{Y}=\mathbf{4 0 4 6} \sim \mathbf{4 . 0}$

So if a CSOM patient with cholesteatoma, has moderate to severe conductive hearing loss with a hearing threshold of 56-60 dB, has an $\mathrm{ABG}$ value $\geq 40$ $\mathrm{dB}$, and a female patient will have a higher intraoperative ossicular status score of 4 which means a condition where the malleus, incus and stapes have experiencing destruction.

\section{Discussion}

\section{Characteristics of research subjects}

In this study, 64 patients who met the inclusion criteria were included as research subjects. Based on gender, there were 33 female subjects (51.6\%) who had CSOM, compared to $48.4 \%$ of male subjects. This is in accordance with research by Inardi et al (2020) at Kariadi Hospital Semarang which found that the proportion of the sex of CSOM patients out of a total of 
100 patients was more in women, namely $55.8 \%$ while in men it was $44.2 \%$. Similarly, research by Singh et al (2018) found that there were slightly more women (53.9\%) than men (46.1\%). Research by Patill et al (2015) also found the ratio of women to men in CSOM patients was 1.77:1. Research by Deviana and Indrasworo (2016) in Malang also found that there were slightly more CSOM patients in women, namely 55\%. In this study, the difference in the proportions that are not too far indicates that gender is not a risk factor for CSOM.

The average age of the subjects was 28 years with the most research subjects in the productive age group, namely the age of 16-30 years. In developing countries, the population is dominated by young adults. The second and third decades are the age when there is an increase in academic potential and the foundation of work which is the reason for patients to come for treatment optimally in that age group because hearing loss due to CSOM will significantly hinder these activities. With increasing age, the incidence of CSOM decreases to $1.7 \%$ for those aged $>50$ years.

Mild hearing loss often goes unnoticed by the patient, so patients generally seek treatment if there is significant hearing loss with progressive disease. The most frequent length of illness for CSOM subjects in this study was $\geq 5$ years. This is in line with the research of Toari et al (2018) which found that illness $\geq$ the most frequent5 years was $50.6 \%$. This shows that in developing countries, awareness of ear and hearing health problems to seek treatment as soon as possible is still very lacking.

Based on the status of the ossicular circuit, the majority of subjects had type $\mathrm{O}(\mathrm{M}+\mathrm{I}+\mathrm{S}+)$ which was $31.3 \%$ of all CSOM subjects, followed by type $\mathrm{F}$ with $21.9 \%$ and type $\mathrm{E}$ and type D with $14.1 \%$ each. The most common necrosis was the incudostapedial joint, the lenticular process and the distal portion of the processus longus incus, followed by destruction of the stapes. The most commonly affected erosion is the incus because of its fragile structure and its location which is most often exposed to air which facilitates infection in the perforated tympanic membrane and which lacks blood supply to the bone. Ossicular erosion of more than 1 ossicle (multi-ossicular) is said to be more common than erosion of a single ossicle. Therefore, in CSOM with ossicular erosion, type D or type $\mathrm{C}$ are more common.

Based on the presence of cholesteatoma, this study found that about $56.3 \%$ of CSOM patients had cholesteatoma. This study is in accordance with research by Ghanie et al (2017) who found that from 116 CSOM patients, 53.4\% of patients with cholesteatoma were found and $46.6 \%$ without cholesteatoma. Research by Deviana and Indrasworo also found in their research that CSOM patients with cholesteatoma tend to be found more because CSOM patients with cholesteatoma are candidates for mastoidectomy surgery who tend to take precedence considering the complications it can cause.

\section{Relationship between age, gender, type of tympanic membrane perforation, cholesteatoma and granulation tissue with hearing threshold in CSOM}

This study found that only granulation tissue had a significant relationship with hearing threshold value in CSOM patients. Age, gender, type of tympanic membrane perforation, and cholesteatoma were found to have no association with hearing threshold in CSOM patients. The presence of granulation tissue in the middle ear increases the vascularity around the ossicles, which lowers the vibration threshold. This is also in accordance with research by Deviana (2016) which concluded that the presence of granulation in CSOM will increase conductive hearing loss in CSOM patients. Granulation tissue is a common intraoperative finding in CSOM which can inhibit ossicular mobility resulting in conductive hearing loss.

Hearing loss is more dependent on the size of the perforation, this is because the main mechanism of hearing loss due to perforation of the tympanic membrane is reduced driving pressure across the tympanic membrane so that it does not depend on the location of the operation. Research by Dudda et al (2018) Kartanaka India found that in safe type CSOM patients, the mean AC threshold was significantly different between small and large tympanic membrane perforations. It was found that with the small 
perforation of the tympanic membrane, the average hearing threshold was $31.18 \pm 7.46 \mathrm{~dB}$, while the subtotal perforation of the hearing threshold was found to be higher at $46.61 \pm 7.02 \mathrm{~dB}$. In this study, the perforation area and location were not taken into account. The difference in hearing threshold at the same perforation size can be caused by the volume of the middle ear and mastoid cavity of each ear of CSOM patients.

This study found that cholesteatoma did not have a significant relationship with hearing threshold values in CSOM patients. This is in accordance with research by Patil et al (2015) who stated that there was no significant difference between cholesteatoma and hearing threshold. Mishra et al (2020) in their study also said that hearing loss can also be obtained with a mild degree even though the pathological process is very severe. Cholesteatoma can serve as a transmission bridge for acoustic energy so that the pure tone audiometric image obtained does not always reflect the true state of the ear transmission system. ${ }^{6}$

\section{Relationship between age, gender, type of tympanic membrane perforation, cholesteatoma and granulation tissue with air bone gap in CSOM.}

In this study, no confounding variables were found that had a significant effect on ABG. This is in line with research by Patil et al (2015) who stated that there was no significant difference between tympanic membrane perforation and ABG ( $\mathrm{p}=0.959)$. However, Dudda et al (2018) found that ABG differed significantly between the size of large and small tympanic membrane perforations, ABG of $33.5 \mathrm{~dB}$ was found in subtotal perforations. In this study, the size of the perforation was not taken into account and only analyzed the type of perforation.

In this study, the length of illness did not significantly affect the ABG. This is contrary to research by Inardi et al (2020) which states that ABG is associated with length of illness. In this study, the duration of pain was different from the duration of discharge from the ear or the duration of otorrhoea. In this study, cholesteatoma and granulation did not significantly affect ABG. The presence of pathological tissues such as cholesteatoma and granulation can serve as a transmission bridge for acoustic energy so that the ABG does not always indicate the true state of the conduction system.

\section{Relationship of age, gender, type of tympanic membrane perforation, cholesteatoma and granulation tissue with intraoperative ossicular status in CSOM.}

Age was proven to be a confounding variable affecting the intra-operative ossicular status of CSOM patients. The third ossicular damage (score 4) was found to be the most in the 45-60 year age group as much as 44\%. Several studies state that hearing loss in CSOM patients is associated with increasing patient age, this can be caused because CSOM is a chronic process. Dewi et al said the high incidence of CSOM at the age of less than 10 years is caused by the relatively short and straight anatomy of the Eustachian tube, poor hygiene and healthy behavior, low immune status, making it easy to suffer from upper respiratory tract infections that cause persistent and worsening otorrhoea. ossicular state. ${ }^{6,14}$

Type of tympanic membrane perforation proved to be a confounding variable that affects the intraoperative ossicular status of CSOM patients. In this study, erosion of the three ossiculars (ossicular status score 4) was found to be the most common in total perforations (45\%) followed by attic perforations (33). In this study, the location and size of the perforation were not assessed, but in total perforation that covers the posterior part, it will increase ossicular damage, as well as in the attic which indicates a dangerous type of CSOM that we know that the presence of cholesteatoma will increase ossicular damage. 10

In this study, cholesteatoma was found to have a significant relationship with intraoperative ossicular status scores. This is in accordance with a study by Haidar et al (2015) who found that ossicular erosion was more common in CSOM with cholesteatoma (69.3\%) than in CSOM without cholesteatoma (13.9\%) from 279 ears of patients with CSOM. More than two thirds of CSOM patients with cholesteatoma experience ossicular discontinuity. Likewise with the study of 
Ghosh et al (2019) which stated that ossicular discontinuity was found in $87.5 \%$ of patients with cholesteatoma. Kahshyap et al (2015) found that ossicular damage is a hallmark of CSOM with cholesteatoma. Akarcay et al (2019) found that ossicular erosions were found in CSOM patients with granulation tissue $(31.8 \%)$ and or without granulation tissue or cholesteatoma (12.7\%).8,9

In this study, the length of illness was not found to have a significant effect on ossicular status. This is in contrast to the study by Jayakumar et al (2016) who found that the length of illness of CSOM more than 10 years was found to be statistically significant with preoperative ossicular status in CSOM patients. A study by Mishra et al (2020) found that ossicular erosions were seen five times more frequently in wet and inflamed ears than in dry ears. Srinivas et al (2014) also said that CSOM patients with dry ears did not have ossicular discontinuities, whereas CSOM patients with persistent otorrhoea had more ossicular defects. According to the researchers, the length of illness did not affect the ossicular status because what affected the ossicular damage was how long the otorrhoea and the type of otorrhoea were, whether the ear was dry, persistent otorrhoea or intermittent otorrhoea. Persistent otorrhoea in the absence of a dry ear phase indicates ongoing inflammation and infection and the longer this infection lasts the greater the ossicular damage. 6

\section{Correlation between intra-operative ossicular status with hearing threshold and air bone gap in CSOM patients.}

In this study, there was a significant relationship between ABG variable and hearing threshold on ossicular status scores. The higher the ABG and the hearing threshold, the higher the ossicular status score and vice versa. If you get an ossicular status score of 0 which means the malleus incus ossicular status and the stapes are intact, it will reduce the hearing threshold value $(\mathrm{p}=0.001, \mathrm{R}=-0.418)$ and $\mathrm{ABG}$ $(\mathrm{p}<0.005, \mathrm{R}=-0.552)$ in OSMK patients. If you get an ossicular status score of 3 which means malleus erosion and intact stapes or status with stapes fixation, it will increase the hearing threshold value $(\mathrm{p}=0.002$, $\mathrm{R}=0.382)$ and ABG $(\mathrm{p}<0.005, \mathrm{R}=0.541)$ in OSMK patients. If you get an ossicular score of 4 which means that all three ossiculars have been destroyed, it will also increase the hearing threshold ( $\mathrm{p}=0.041, \mathrm{R}=0.256)$. So this study found that the higher the hearing threshold value, the higher the ossicular status score. Likewise, the higher the ABG value, the higher the ossicular status score.

This study is in line with the findings of Mishra et al (2020) who stated that the ossicular integrity status was more frequently impaired in patients with moderate to moderately severe conductive hearing loss as measured by pure tone audiometry. This is also in accordance with the research of Dudda et al (2018) which said that the hearing threshold in CSOM was related to the condition of the ossicular circuit. There were significant differences in pure tone audiometric features between the group with ossicular erosion and the intact ossicular group. A study by Bayat et al (2019) found that the average hearing threshold of CSOM patients with ossicular damage was higher, namely 48 $\pm 13.17 \mathrm{~dB}$, while in intact ossicular it was $44.75 \pm$ 9.40. Shinta et al (2018) also found a similar thing where there is a relationship between the average hearing threshold value with ossicular status and an increase in the average hearing threshold value can predict the presence of pre-operative ossicular erosion. In addition, the hearing threshold was worse in patients with two or three ossicular defects compared with no ossicular defects. ${ }^{6,7}$

In the research of Ghosh et al (2019), it was found that a wide $A B G$ picture, especially at high frequencies, will show ossicular discontinuities. ABG values $>40 \mathrm{~dB}$ were found in $60 \%$ of CSOM patients with cases of ossicular discontinuity. The mean ABG in the intact ossicular group was $24.09 \pm 9.56 \mathrm{~dB}$ and the eroded ossicular group was $31.02 \pm 9.83 \mathrm{~dB}$. Statistically significant differences in mean ABG in the intact and erosional ossicular groups were also found in the study by Srinivas et al (2014). A narrow ABG indicates bone integrity, while a wide $A B G$ predicts bone erosion. Harakare et al (2020) found similar results where ABG $>40 \mathrm{~dB}(\mathrm{p}<0.001)$ was statistically significantly 
associated with the incidence of ossicular erosion. Research by Inardi et al (2020) found that ossicular status was also significantly associated with ABG. This shows that the hearing threshold and ABG are reliable parameters for the diagnostic process and predicting ossicular conditions. 9

To control for confounding variables and assess how the strength of the relationship between the independent variable and the dependent variable, namely the factors associated with the intra-operative ossicular status score, multivariate analysis was carried out on the variables with $p$ value $<0.25$. The analysis was carried out using linear regression because the dependent data was in the form of numerical variables, the method used was Backward $L R$. The results of linear regression showed that gender, cholesteatoma, hearing threshold and ABG had a significant effect on the status of the intraoperative ossicular status score. If the subject has cholesteatoma, it will increase the ossicular score by 0.648 with a $p$ value of 0.055 . If the subject has a hearing threshold of 56-60 dB or moderate degree of hearing loss, it will increase the ossicular score by 0.648 with a $p$ value of 0.026 . If the subject has $A B G>$ $40 \mathrm{~dB}$, it will increase the ossicular score by 1.196 with a $p$ value of 0.012 . And if the gender is female, it will not reduce the ossicular score by 0.548 with a $p$ value of 0.077. This study is in accordance with research by Inardi et al (2020) who found that ossicular status is a risk factor that has the strongest relationship with the incidence of $\mathrm{ABG}$ in CSOM ( $\mathrm{p}=0.001$ and $\mathrm{PR} 7.12)$. Likewise with the research of Ghosh et al (2019) which found that ossicular discontinuities were found to be more common in $\mathrm{ABG}>40 \mathrm{~dB}$ with $\mathrm{p}<0.001 .9$

\section{Conclusion}

Age, type of tympanic membrane perforation, cholesteatoma, and granulation tissue were factors that significantly influenced the intraoperative ossicular status score. Granulation tissue is a confounding variable that has a significant effect on hearing threshold values. There is a positive correlation with a strong strength between hearing threshold values and intra-operative ossicular status scores in
CSOM patients at Dr Mohammad Hoesin Hospital. There is a positive correlation with a strong strength between ABG scores and intra-operative ossicular status scores in CSOM patients in Dr Mohammad Hoesin General Hospital Palembang.

\section{References}

1. Shariff EA. Analysis of hearing loss by pure tone audiometry in patients with chronic suppurative otitis media. National Journal of Physiology Pharmacy and Pharmacology. 2019; 9(6): 515-518.

2. Mishra D, Nagi RS, Sharma K. To evaluate the correlation between preoperative otoscopic features, pure tone audiometric findings and intraoperative ossicular chain status in patients with chronic otitis media. International Journal of Otolaryngology and Head \& Neck Surgery. 2020; 9:141-148.

3. Ghosh NC, Saha KL, Akhtar N, Islam MM, Jewel AM, Hasan M. Relationship of preoperative hearing loss with peroperative ossicular discontinuity in chronic otitis media. Bangladesh Journal of Otorhinolaryngology. 2019; 25(2): 94-101.

4. Bayat A, Saki N, Nikakhlagh S, Farshad MA, Lotfinia M. Ossicular chain defect in adults with chronic otitis media. International Tinnitus Journal. 2019; 23(1): 6-9.

5. Chole RA, Sudhoff H. Chronic otitis media, mastoiditis and petrositis. In: Niparko JK, editors. Cummings otolaryngology head and neck surgery. $7^{\text {th }}$ edition. Philadelphia: Elsevier Mosby.2020; 1964-78.

6. Wackym PA, Snow JB, editors. Ballenger's otorhinolaryngology: Head and neck surgery. $18^{\text {th }}$ edition. Connecticut: People's Medical Publishing House. 2016; 1-16.

7. Weber PC, Khariwala S. Anatomy and physiology of hearing. In: Bailey BJ, Johnson JT, Shawn D editors. Head \& Neck SurgeryOtolaryngology. $5^{\text {th }}$ Edition Volume 2. 
Philadelphia: Lippincott Williams \& Wilkins. 2014; 2253-73.

8. Mittal R, Christopher, Gerring R, Mittal J, et al. Current concepts in the pathogenesis and treatment of chronic suppurative otitis media. Journal of Medical Microbiology. 2015; 64: 1103-1116.

9. Imad, Billah M, Sanaullah, Farhad S. Bacteriology and culture sensitivity for ear discharge in chronic otitis media. JSMC. 2017; $7(2)$ : 83-85.

10. Browning GG, Merchant SN, Kelly G, Swan IR, et al. Chronic otitis media. In: Gleeson M, Burton JM Editor. Scott-Brown's Otolaryngology. 8th Edition. Great Brittain: CRC Press Taylor and Francis Group. 2018. 3395-3445.

11. Prakash, Afshan T. Role of high resolution computed tomography of temporal bone in preoperative evaluation of chronic suppurative otitis media. International Journal of Otolaryngology and Head Neck Surgery. 2018; 4(5): 1287-1292.

12. Nayak GK, Barhma D, Chatterjee P, Sharma P. Ossicular chain status in chronic suppurative otitis media. Journal of Dental and Medical Sciences. 2016;15(3): 20-23.

13. Chatterjee, Pritam, Khanna S, Talukdar R. Role of high resolution computed tomography of mastoids in planning surgery for chronic suppurative otitis media. Indian $\mathrm{J}$ Otolaryngology Head and Neck Surgery. 2015; 67(3): 275-280.

14. Fischer N, Schartinger VH, Dejaco D, et al. Readout-segmented echo-planar dwi for the detection of cholesteatomas: correlation with surgical validation. AJNR Am J Neuroradiol. 2019; 40:1055-1059.

15. Bhalla AS, Singh A, Jana M. Chronically discharging ears: evalution with high resolution computed tomography. Polish Journal of Radiology. 2017; 82: 478-489.

16. Sanna M, Sunose H, Mancini F, Russo A, et al. Chapter 14: Canal wall down (open) tympanoplasty. in: middle ear and mastoid microsurgery. 2nd Edition. New York: Thieme. 2012.

17. Kathleen C, Campbell M. Audiology. In: KJ Lee's essential otolaryngology head and neck surgery. 12th Edition. New York: Mc-Graw Hill Education. 2019; 257-71.

18. Adegbiji WA, Olajide GT, Olajuyin OA, Olatoke F, Nwawolo CC. Pattern of tympanic membrane perforation in tertiary hospital in Nigeria. Nigerian Journal of Clinical Practice. 2018: 21; 1044-1049.

19. Dawood MR. Frequency dependence hearing loss evaluation in perforated tympanic membrane. Int Arch Otorhynolaryngol. 2017: 21 ; 336-342.

20. Srinivas C, Kulkarni NH, Bhardwaj NS, Kottaram PJ, et al. Factors influencing ossicular status in mucosal chronic otitis media - an observational study. Indian Journal of Otology. 2014; 2(1): 16-19.

21. Albera R, Federico D, Filipini C, Albera A, Canale A. Ossicular chain lesion in tympanic perforations and chronic otitis media without cholesteatoma. The Journal of International Advanced Otology. 2015; 11(2): 143-146.

22. Kumar D, Manorama S. Intraoperatif status of ossicles in patients of chronic suppurative otitis media: a study of 150 cases. Journal of Dental and Medical Sciences. 2020; 5(16): 21 24.

23. Horvath T, Lukacs D, Horvath B, Ferenci T, Liktor B. Does The Type of Ossicular Chain Lesion Affect Outcomes in Chronic Suppurative Otitis Media Without Cholesteatoma? J Int Adv Otol. 2019; 15(1) :28-33.

24. Wiatr M, Składzień J, Stręk P, PrzeklasaMuszyńska A, Wiatr A. Chronic otitis media with granulation is a poor prognostic factor for hearing improvement and development of intracranial complications. J Int Adv Otol. 2019; 15(1) :12-17. 
25. Kashyap SK, Singh B, Purohit JP, Chandrabhan, Singh AP, Azeem M. Incidence of ossicular chain pathology in tubotympanic type of CSOM. J Evol Med Dent Sci. 2015; 4(67) :11701-11707.

26. Jayakumar CL, Inbaraj LR, Pinto GJO. Preoperative Indicators of Ossicular Necrosis in Tubotympanic CSOM. Indian $\mathrm{J}$ Otolaryngol Head Neck Surg. 2016; 68(4) :462-467.
27. Harkare VV, Khadakkar SP, Deosthale NV, Dhoke PR. Study of Preoperative Indicators of Ossicular Defect in Mucosal Type of Chronic Suppurative Otitis Media. J Evol Med Dent Sci. 2020; 9(9) :668-672. 